\title{
CUANDO OCTAVIO PAZ LEYÓ A SOR JUANA: A VUELTAS CON LAS TRAMPAS DE LA FE Y SUS RESPUESTAS
}

\author{
WHEN OCTAVIO PAZ READ SOR JUANA: \\ THE TRAPS OF FAITH AND ITS ANSWERS
}

\section{BEATRIZ ARACIL*}

\section{RESUMEN}

Pasados más de treinta años de la primera edición del ambicioso ensayo de Octavio Paz Sor Juana Inés de la Cruz o Las trampas de la fe, el objetivo del presente trabajo es plantear algunas cuestiones que permitan contextualizar y explicar más cabalmente la significación de este libro en la ya inabarcable tradición crítica sobre sor Juana Inés de la Cruz, e intentar aportar asimismo una breve interpretación de su papel en el conjunto de la producción del poeta y ensayista mexicano.

Palabras clave: México virreinal, poesía novohispana, ensayo mexicano, Octavio Paz, Sor Juana Inés de la Cruz.

\section{ABSTRACT}

After over thirty years since the first edition of Octavio Paz's ambitious essay, Sor Juana, Or the Traps of Faith, this paper raises some questions to better contextualize and explain the significance of this book within the vast critical tradition of Sor Juana Inés de la Cruz, as well as to try to contribute with a brief interpretation of its role in the overall production of the Mexican poet and essayist.

Keywords: Colonial México; New Spanish poetry; Mexican essay; Octavio Paz; Sor Juana Inés de la Cruz.

Recibido: 17.07.15. Aceptado: 10.11.15.

* Profesora Titular de Literatura Hispanoamericana. Universidad de Alicante. Alicante, España. Correo electrónico: beatriz.aracil@ua.es 
Me acuerdo que Octavio Paz pensaba que hablar de sor Juana era como hablar de sí mismo.

(Margo Glantz, Yo también me acuerdo)

$\mathrm{E}$ N 1982 SALÍA A LA LUZ simultáneamente en México (FCE) y en España (Seix Barral) el libro de Octavio Paz Sor Juana Inés de la Cruz o Las trampas de la fe. Se trataba del ensayo más ambicioso de Paz, tanto por su extensión como por su temática: alrededor de 600 páginas dedicadas a la que fue la máxima figura de las letras en la América Virreinal, calificada en su época como "Décima musa", "Fénix de los Ingenios" o "Sibila Americana"; una poeta que reunió, como señalaba el propio Paz, "la excelencia, la abundancia y la diversidad" (1995, p. 620)․ Páginas, además, que no se centraban solo en la obra de sor Juana, porque su intención, señalada desde el prólogo, era

... insertar la doble singularidad de Sor Juana, la de su vida y la de su obra, en la historia de su mundo: la sociedad aristocrática de la ciudad de México en la segunda mitad del siglo XVII (1995, p. 15)².

El libro era fruto de varios años de trabajo y estaba vinculado a algunas escrituras previas. El propio Paz explicaba asimismo en el prólogo que sor Juana había sido para él una preocupación recurrente y citaba como primer antecedente de esta obra amplia un artículo publicado en la revista Sur en 1951 (con motivo de la celebración del centenario de su nacimiento ${ }^{3}$ ), aunque en realidad la reflexión sobre sor Juana había surgido ya en El laberinto de la soledad (1950), donde intentaba explicar a la autora como figura que, a un tiempo, era fruto del orden colonial y lo transgredía, y donde, además,

${ }^{1}$ A lo largo del presente estudio citaré de esta edición, que reproduce la edición española de 1982 , salvo en aquellas ocasiones en las que hago referencias a fragmentos incorporados en ediciones posteriores, en las que seguiré la edición de las Obras completas.

${ }^{2}$ De hecho, el objetivo de Paz iba a quedar reflejado claramente en el título que había elegido en un principio para el libro: Sor Juana Inés de la Cruz. Su tiempo, su vida, su obra, título que descartó por ser "bastante gris", como confiesa a su editor español Pere Gimferrer (Paz, 1999, p. 218; volveré más adelante al título definitivo). Debo las referencias a este ensayo en la correspondencia entre Paz y Gimferrer a la generosa aportación de Judith Farré Vidal (CSIC, España), quien ha trabajado la relación entre ambas figuras en "La escritura indeleble del incendio: Octavio Paz en Barcelona" (Congreso Internacional "Octavio Paz y José Revueltas: las dos caras de México", Düsseldorf, dic. 2014).

${ }^{3}$ Siguiendo la información aportada por el padre Calleja, todos los investigadores convenían en fechar el nacimiento de sor Juana en 1651 hasta que en 1962 Alberto G. Salceda encontró un acta de bautismo de una niña llamada Inés, cuyos padrinos eran Miguel Ramírez e Isabel Ramírez, que probablemente corresponde a la de nuestra autora. El propio Paz se hará eco de este dato en su ensayo (1995, pp. 96-97). 
mostraba su interés por los dos grandes textos autobiográficos de la monja novohispana (la Respuesta a sor Filotea de la Cruz y el Primero sueño), vinculaba su renuncia final a las letras con el contexto político que vivió la ciudad de México a partir de $1692^{4}$ y destacaba la significación de esa renuncia, de ese silencio último de la autora, porque "si en la obra de Sor Juana la sociedad colonial se expresa y se afirma, en su silencio esa misma sociedad se condena" (1950, p. 118).

El texto de 1951 aludido en el prólogo, que apenas difiere en algunos párrafos del que incluiría en 1957 en Las peras del olmo $0^{5}$ iniciaba prácticamente donde había finalizado el de El laberinto: esos años finales marcados por la escritura de la Carta atenagórica y la Respuesta y la inmediata renuncia de sor Juana, su "silencio", solo explicable "dentro de la historia de la cultura colonial" (Paz, 1951; 2001, p. 176), para referirse a continuación al tema del amor en su poesía y hacer una primera aproximación interpretativa al Primero sueño ${ }^{6}$.

Después vendrían las clases en Harvard (a partir de 1971) y las conferencias en el Colegio Nacional (en 1974), de cuyo material -según él mismo explica- surgiría la idea del libro (Paz, 1995, pp. 11-12), idea que tardaría bastante tiempo aún en materializar y que sufriría numerosos altibajos en el proceso de escritura hasta la redacción de los últimos capítulos entre fines de 1980 e inicios de 1981, tal como se refleja en las cartas que dirige por esos años a su editor Pere Gimferrer ${ }^{7}$. El resultado de esa ardua tarea, en

${ }^{4}$ En ese año de 1692 tiene lugar un motín en México provocado por la mala gestión del conde de Galve ante la situación de carestía en la que había quedado sumida la ciudad a raíz de las inundaciones; la consecuencia política más grave fue la destitución del virrey y su sustitución temporal por el entonces arzobispo Francisco de Aguiar y Seijas.

${ }^{5}$ Incluido a su vez como "primer texto del autor sobre sor Juana Inés de la Cruz" en sus Obras completas III (Paz, 2001, pp. 174-188).

${ }^{6}$ Enrico Mario Santí incluye entre estas escrituras previas sobre la autora el escaso par de páginas que Paz le dedica en su "Introducción a la historia de la poesía mexicana", finalmente publicada en la Anthologie de la poésie mexicaine (París, UNESCO, 1952; las páginas pueden consultarse en Paz, 2001, pp. 41-43), pero destaca como esencial el citado ensayo de 1951 (Santí, 1997, pp. 275-280).

7 "Tuve que dejar de lado, incluso, el libro de Sor Juana, que escribo a ratos perdidos y con una lentitud desesperante", explica a Gimferrer en octubre de 1977 (Paz, 1999, p. 157), aunque añade en siguientes párrafos: "Quizá podré terminarlo este año. Ya llevo más de la mitad” (159). En carta de enero de 1979, reconoce, sin embargo: "En cuanto al libro de Sor Juana: no avanza. Estoy paralizado. El tema se ha ido alejando poco a poco y tendré que hacer un gran esfuerzo para volver a él. Es lástima porque me falta un capítulo y reescribir los dos últimos” (179). Por fin, en noviembre de 1980, escribe: "Espero terminar en los próximos meses del año próximo el libro de Sor Juana, al que he vuelto al fin, después de haberlo dejado desde hace cerca de tres años” (211). A pesar de las dificultades que le supone escribir en la ciudad de México, la obligación de finalizar otros proyectos e incluso la enfermedad, el autor sí cumplirá esta vez su compromiso. 
cualquier caso, le compensó con creces: tanto la importancia del libro en el conjunto de la producción de Paz como su influencia en la bibliografía sobre sor Juana quedaron fuera de toda duda ya en los años inmediatamente posteriores ${ }^{8}$, y especialmente tras la publicación de la traducción al inglés del texto en 1988, con el consiguiente eco entre la crítica anglosajona9.

Sor Juana Inés de la Cruz o Las trampas de la fe marcó un punto de inflexión en los estudios sobre la autora novohispana, y, sin embargo (o precisamente por ello), a más de treinta años de la primera versión del texto (que el propio Paz iría retocando en ediciones posteriores), la lectura de este libro exige una contextualización y reubicación del mismo en la ya inabarcable tradición crítica sobre sor Juana Inés de la Cruz, al tiempo que una valoración interpretativa del papel de la obra como parte de la producción literaria del poeta y ensayista mexicano. El objetivo del presente trabajo será aportar algunas ideas que favorezcan esa lectura crítica del ensayo en las dos líneas propuestas.

\section{PAZ Y LA TRADICIÓN CRÍTICA SOBRE SOR JUANA: LOS ENIGMAS Y SUS RESPUESTAS}

Leer el libro de Paz hoy (como hace tres décadas) debería implicar la asunción de un rasgo esencial, pero a menudo olvidado, del texto que ha sido puesto de relieve en fechas recientes por Mónica Quijano:

Sor Juana Inés de la Cruz o las trampas de la $f e(. .$.$) se inscribe en un lugar$ especial: por su forma podría adscribirse a la biografía de corte literario

\footnotetext{
${ }^{8}$ Pensemos en las elogiosas reseñas a la obra redactadas por Ramón Xirau ([1982] 1997, pp. 147-158), Jaime Alazraki (1984) o Dante Liano, quien comenzaba su texto reconociendo que "El libro de Paz Sor Juana Inés de la Cruz o Las trampas de la fe es uno de esos raros casos en que una publicación equivale a un acontecimiento. No solo para los conocedores de la literatura hispanoamericana sino para todo el ambiente cultural" (1984, p. 102).

${ }^{9}$ En el presente trabajo haré referencia a algunas de las reseñas aparecidas en revistas estadounidenses a los pocos meses de la publicación, como fueron las de Thomas R. Hart (1989), Benjamin Keen (1989) o Gerald W. Haslam (1989). En cualquier caso, hay que considerar la advertencia que hacía pocos años después, a propósito de esta versión en inglés, Georgina Sabat (quien ya había dedicado a su vez una reseña a la edición mexicana en 1985): “Creo puede decirse sin equivocación que ningún otro libro, desde la aparición de éste en España y en México, ha recibido tanta atención del público y ha sido objeto de tan alto número de reseñas en este país así como en el extranjero. Se ha comentado el libro en muchas lenguas: en español, inglés, francés, italiano, portugués y alemán. Críticos literarios de escuelas e intereses muy variados, novelistas y ensayistas famosos, historiadores, filósofos... se han ocupado del libro de Paz; sería ya casi imposible recoger esa gran variedad de comentarios dispersos" (1995, pp. 106-107).
} 
y ensayístico, ya que no sigue las reglas metodológicas de una escritura académica. Sin embargo, el pacto de veracidad que implica toda escritura histórica está presente. Asimismo, el libro de Paz ha sido leído, citado y criticado de manera amplia por universitarios, quienes lo han considerado bajo criterios académicos. Esto hace de éste un texto que se mueve entre dos mundos institucionales: el literario e intelectual y el académico $(2009$, p. 8$)$.

El propio Paz estableció esta doble condición de un texto concebido como ensayo (esto es, como una obra literaria ${ }^{10}$ ), pero que aspiraba a ser valorado como trabajo académico (e incluso como el trabajo académico definitivo sobre sor Juana): Paz estuvo atento a la bibliografía crítica sobre la autora ${ }^{11}$; se documentó concienzudamente respecto de los más pequeños detalles ${ }^{12} \mathrm{y}$, lo que es más importante, a pesar de ser consciente de su condición de escritor, reclamó el valor académico de su trabajo. No puede entenderse de otro modo su polémica con Elías Trabulse (y sus defensores Jorge Alberto Manrique y Edmundo O'Gorman), en los años previos a la publicación del ensayo, en escritos en los que reclama haber sido el primero en señalar a Kircher como la fuente del hermetismo neoplatónico en sor Juana y lamenta que sus conferencias de 1974 no hayan sido tenidas en cuenta porque es "un simple escritor y no es miembro de las cofradías y hermandades académicas" (Paz, 2001, p. 1334), o el interés por incorporar a la tercera edición de su obra (1983) la Carta de Monterrey dada a conocer por Aureliano Tapia apenas dos años antes (1981) precedida de unos párrafos suyos (Paz, 2001, pp. 1305-1321), por tratarse del documento que probaba que él tenía razón al intuir que sor Juana había roto con su

\footnotetext{
${ }^{10}$ Así lo presentaron, en sus respectivas reseñas a las ediciones mexicana y española, Asunción Lavrin, que habló de cómo “The writer's elegant prose, combined with his literary intuition and his powerful poetic imagination, have produced a book which is difficult to stop reading” (1984, p. 589), y sobre todo Dante Liano, quien, aun reconociendo que el libro tenía "páginas ricas de investigación documental", afirmaba: "Paz (...) no se ha planteado el imitar a la crítica académica sino producir un monumento (parafraseando a Borges: un bien labrado monumento de signos) en donde el ensayo recobra su puesto y su vigor dentro de la tradición artística hispanoamericana” (1984, p. 105).

${ }^{11}$ Algo que se observa especialmente en las amplias notas a pie del apartado referido al Primero sueño (Paz, 1995, pp. 469-507).

${ }^{12}$ Así, por ejemplo, en 1977, pide a Gimferrer "una biografía de Carlos II del Duque de Maura" con la que espera obtener información sobre uno de los validos del rey, el Duque de Medinacelli, hermano mayor del marqués de la Laguna, "el Virrey que protegió a Sor Juana y a cuya mujer, María Luisa Manrique de Lara, Condesa de Paredes, estuvo unida por una suerte de amistad amorosa" (Paz, 1999, pp. 160-161).
} 
confesor Antonio Núñez de Miranda casi una década antes de la polémica publicación de la Atenagórica ${ }^{13}$.

Por otro lado, me parece necesario advertir que, aunque la tarea de redacción del ensayo fue -como hemos visto- amplia, los puntos esenciales de reflexión estaban resueltos desde fecha relativamente temprana: son los que tienen que ver con un intento de responder a "los dos grandes enigmas que tanto han intrigado a los que se han acercado a su figura: las razones que la movieron a profesar y las que la llevaron a renunciar a las letras" (Paz, 1995, p. 91), especialmente este último ${ }^{14}$, que es el que da título al libro a pesar de que, como el mismo Paz reconoce, "las trampas de la fe" no es una frase que pueda aplicarse a toda la vida de sor Juana y "tampoco define el carácter de su obra" (1995, p. 17).

En ese intento de resolver "el enigma de Sor Juana Inés de la Cruz", que es a su vez "muchos enigmas, los de su vida y los de su obra" (Paz, 1995, p. 13), Paz se encuentra, como los autores que lo preceden, con una relativa pero crucial falta de documentos, y ello le obliga a "llenar el vacío" con "intuiciones", con puras elucubraciones. Es cierto que están esos dos textos autobiográficos: el Primero sueño y, sobre todo, la Respuesta a sor Filotea, pero el primero es difícilmente interpretable más allá de la defensa y fracaso (al menos parcial) con el que según Paz se muestra "el acto de conocer", y el segundo, con ser una autoafirmación y una aclaración personal de diversos momentos vitales, no explica todo y queda a las puertas de la renuncia final plasmada en las "fórmulas usadas" de esos documentos firmados también por sor Juana: la "Petición que en forma causídica presenta al Tribunal Divino la Madre Juana Inés de la Cruz, por impetrar perdón de sus culpas” (Cruz, 1957, pp. 520-521) y, sobre todo, la "Protesta que, rubricada con su sangre, hizo de su fe y amor a Dios la madre Juana Inés de la Cruz, al tiempo de abandonar los estudios humanos para proseguir, desembarazada de este

\footnotetext{
${ }^{13}$ Paz pidió además a Gimferrer que también apareciera en la edición de Seix-Barral esa "carta de Sor Juana (más bien dicho: una copia de principios del XVIII, poco después de su muerte, de una carta suya) que confirma todo lo que sostengo en la sexta parte del libro" (1999, p. 246), apéndice que, sin embargo, no fue incluido en posteriores ediciones españolas.

A pesar de todos estos esfuerzos, sin embargo, era evidente que nuestro autor no había realizado una investigación académica, lo cual se reflejaba en aspectos tan significativos como el destacado por Frederick Luciani en su reseña a esa tercera edición mexicana ampliada: "la ausencia de una bibliografía crítica", y lo que de ello se derivaba: "Aunque las notas textuales reconocen debidamente la aportación de los sorjuanistas más eminentes de ayer y de hoy, no queda muy claro hasta qué punto difiere Paz del trabajo de otros hispanistas que no reciben mención en su libro" (1985, p. 398).

${ }^{14}$ Un aspecto presente incluso, como hemos visto, en El laberinto de la soledad (Paz, 1950, pp. 117-118).
} 
afecto, el camino de la perfección" (Cruz, 1957, pp. 518-519), documento que una vez leído no deja claro, según nuestro autor, ese "abandono" que anuncia el título.

Paz se atreve entonces a ofrecer una imagen concreta de su autora, la que él ha concebido, imagen que, por el carácter ensayístico de su libro, no siempre tiene que "probar" a través de los documentos; es su propia lectura (aunque influida por autores como Dorothy Schons o Darío Puccini): la de una mujer que elige la condición religiosa como único modo de mantener su pasión intelectual, que triunfa en un mundo cultural masculino, pero que sucumbe ante la "conspiración" de un poder eclesiástico (símbolo de todo poder autoritario y burocratizado) que no puede admitir esta transgresión de las normas establecidas ${ }^{15}$.

Esta imagen contradice (al menos parcialmente) la ofrecida por una parte de la crítica que le precede, y es por ello que el ensayista mexicano construye su argumentación en buena medida como "respuesta" fundamentalmente a dos líneas interpretativas que van a preocuparle desde el prólogo hasta las páginas finales: la desarrollada por Ludwig Pfandl en el libro traducido al español con el título Sor Juana Inés de la Cruz: Décima Musa de México (1963), donde, a partir de conceptos psicoanalíticos, se pretende demostrar que en realidad sor Juana es "una personalidad neurótica, en la que predominan fuertes tendencias masculinas" (Paz, 1995,

\footnotetext{
${ }^{15}$ Esta teoría de la conspiración se desarrolla en la última sección del libro, que le da título, dedicada a los años finales de sor Juana a partir de 1690, fecha en la que, como es sabido, "sor Filotea de la Cruz" (pseudónimo del obispo de Puebla, Manuel Fernández de Santa Cruz) publica el único texto teológico de sor Juana, la Carta Atenagórica, cuyo contenido es un comentario crítico al sermón de un gran teólogo jesuita portugués, Antonio de Vieyra, escrito en 1650 (40 años antes), en el que se intentaba dilucidar cuál fue la mayor fineza (demostración de amor) que Cristo hizo a los hombres antes de morir. Para abordar la problemática de la Atenagórica, Octavio Paz parte de la argumentación de Darío Puccini, quien propone que el obispo Fernández de Santa Cruz publica esta carta con el fin de humillar al arzobispo, con el que tiene una clara rivalidad; ahora bien, si para Puccini sor Juana se convierte en un instrumento en las maquinaciones de Fernández de Santa Cruz, nuestro autor ve en la monja novohispana sus propios motivos para humillar a este arzobispo misógino e intransigente: defenderse a sí misma y a su sexo en la actividad intelectual. Sor Juana no puede prever, sin embargo, el poder que Aguiar va a asumir a partir de 1692, año en que, como ya se ha señalado, la carestía provocada por las inundaciones provoca el motín contra el conde de Galve (y el acceso al poder político de Aguiar) y en el que muere además en España uno de sus valedores, el marqués de la Laguna. Retirado de la polémica el obispo de Puebla y sin el apoyo de su antiguo confesor, el también influyente jesuita Antonio Núñez de Miranda, "si examinaba su situación con frialdad tenía que reconocer que había perdido a sus patronos y que estaba en manos de sus censores” (Paz, 1995, p. 575). Para Paz, el hecho de que sor Juana renuncie en 1693 a su actividad intelectual y done su biblioteca a Aguiar para que la venta sirva de limosna a los pobres es consecuencia no tanto de una verdadera "conversión" religiosa como de los sentimientos de culpa y el cerco al que se ve sometida por esos círculos del poder eclesiástico que censuran su dedicación a las letras (Paz, 1995, pp. 511-608).
} 
p. 13); y la interpretación de la erudición católica, que empieza con el primer biógrafo de sor Juana, el jesuita Diego Calleja (1700), y tiene como figura clave la del gran investigador mexicano Alfonso Méndez Plancarte, editor de sus Obras completas en los cuatro volúmenes de Fondo de Cultura Económica que empiezan a aparecer en 1951; una interpretación que exalta el valor intelectual y literario de la monja, pero que concibe su vida como "un gradual ascenso hacia la santidad" (Paz, 1995, p. 13).

Basándose en los textos de la propia autora y en el contexto cultural en el que desarrolla su obra, Paz rebate el supuesto narcisismo de sor Juana, que Pfandl vincula con tendencias masculinas, en dos sentidos: por un lado, es cierto que la poetisa se observa a sí misma, pero no en un sentido narcisista, "no se mira para admirarse sino que, al admirarse, se mira" (1995, p. 94), es decir, es consciente de su excepcionalidad e intenta explicarla; por otro lado, el contexto cultural de la autora debe ser tenido en cuenta: "Cómo, en una civilización de hombres y para hombres -se pregunta Paz-, puede una mujer, sin masculinizarse, acceder al saber" (1995, p. 94). Hasta aquí la argumentación parece impecable y, sin embargo, sorprendentemente, Paz, que en principio rehúye cualquier intento de "revelar los repliegues de la intimidad de Sor Juana" (1995, p. 260), no puede evitar la tentación de superar al biógrafo alemán en su propio terreno y se lanza en diversos pasajes del ensayo a un análisis de corte psicoanalítico con el que pretende justificar (entre otros aspectos) la relación de sor Juana con lo masculino:

En el caso de Juana Inés, si es verdadera mi suposición, la niña mata a su padre, no a su madre, y esto indica una inversión de sexo y de valores. Doble transgresión: matar a la imagen de su padre y asumir así, no la imagen de la madre, sino la masculina (Paz, 1995, p. 112) ${ }^{16}$.

Análisis cuya debilidad no pasó inadvertida a las primeras lecturas del ensayo ${ }^{17}$ y que ha sido objeto asimismo de críticas posteriores como la de Paciencia Ontañón, quien, en un artículo significativamente titulado "Sor Juana, víctima de los críticos", advertía a propósito tanto de esta interpretación como de la de su antecesor:

\footnotetext{
${ }^{16}$ Cf. Paz, 1995, pp. 111-124; 145; 287-8.

${ }^{17}$ Pueden consultarse a este respecto Lavrin (1984, p. 590); Luciani (1985, p. 398); Keen (1989, p. 580-581); otros autores, en cambio, valoraron positivamente estos intentos por parte de Paz de indagar en la psicología de la monja novohispana (véase Bénassy-Berling, 1983, p. 102; Liano, 1984, p. 105).
} 
He aquí, pues, dos libros más sobre sor Juana. Uno [el de Pfandl] trata de ser un estudio psicoanalítico e -infortunadamente- no lo es en ningún momento. El otro [el de Paz] no trata de serlo, pero recurre en algunas páginas a Freud y a cuestiones psicológicas, con poca fortuna. Algo que hubiese sido innecesario en una obra de alcances diferentes, y que sólo por contaminación de otra incurre en ese terreno tan poco preciso y tan mal apuntalado (1999, p. 190).

Más afortunada para Paz es su respuesta a la "interpretación católica" de la figura de sor Juana, ante la cual se muestra a un tiempo firme y conciliador, sin duda porque es consciente de la calidad intelectual de la mayor parte de sus oponentes. Su objetivo es instalar a la monja novohispana en el espacio de la racionalidad, rebatiendo la construcción "hagiográfica" que toda una tradición ha formado de ella (no en vano apuntaba ya treinta años antes, en El laberinto de la soledad, que la Respuesta y el Primero sueño hacían a sor Juana "ejemplar en sentido muy distinto al que piensan sus panegiristas católicos", 1950, p. 113) ${ }^{18}$. La "pasión edificante” iniciada por la biografía de Calleja -explica Paz en su ensayo- "ha cegado" a insignes investigadores como Ezequiel Chávez o Robert Ricard (Paz, 1995, p. 91) ${ }^{19}$, e incluso al ilustre Méndez Plancarte, quien recibe, por parte del poeta, una

${ }^{18}$ Este enfrentamiento a la imagen de sor Juana ofrecida por la tradición católica fue alabado ya en reseñas como la de Hart (1989, p. 398) o Juan Goytisolo, quien interpretó las conclusiones de Paz a este propósito con afirmaciones más categóricas que las del poeta mexicano: "Las leyendas piadosas y edificantes acerca de la decisión de Juana Ramírez de Asbaje de profesar en el convento de las jerónimas no se fundan en realidad alguna" (1989, p. 23); "La falsificación de la historia transformó hasta el siglo XX la derrota y sumisión de la monja en un rasgo sublime" (27).

${ }^{19}$ Por otro lado, es curioso que Paz omita la adhesión a esa tradición católica de algunos nombres que él mismo cita por su contribución al estudio de la vida y la obra de sor Juana. Es paradigmático el caso de Gabriela Mistral (Paz, 1995, p. 12), quien, en un texto de 1923 (reeditado por la revista Ábside en el significativo año de 1951), había escrito sobre los últimos años de la monja: "Viene el último período. Un día la fatiga la astronomía, exprimidora vana de las constelaciones; la biología, rastreadora minuciosa y defraudada de la vida; y aun la teología, a veces pariente ¡ella misma! del racionalismo. Debió sentir, con el desengaño de la ciencia, un deseo violento de dejar desnudos los muros de su celda de la estantería erudita. / Quiso arrodillarse, en medio de aquélla, con el Kempis desolado por único compañero y con la llama del amor por todo conocimiento. / Tiene entonces, como San Francisco, un deseo febril de humillaciones, y quiere hacer las labores humildes del convento, que tal vez ha rehusado muchos años: lavar los pisos de las celdas y curar la sucia enfermedad con sus manos maravillosas, que tal vez Cristo le mira con desamor. Y quiere más aún; busca el cilicio, conoce el frescor de la sangre sobre su cintura martirizada. / Esta es para mí la hora más hermosa de su vida; sin ella yo no la amaría" (destaco esta frase final porque sería retomada por Méndez Plancarte precisamente para referirse a los años finales de Sor Juana en la semblanza biográfica de su edición (1951, pp. XXXI-XXXII) y más recientemente por Soriano Vallés para uno de sus libros: La hora más bella de Sor Juana, México, Consejo Nacional para la Cultura y las Artes, 2008).

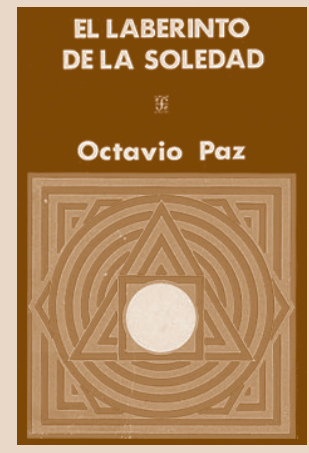




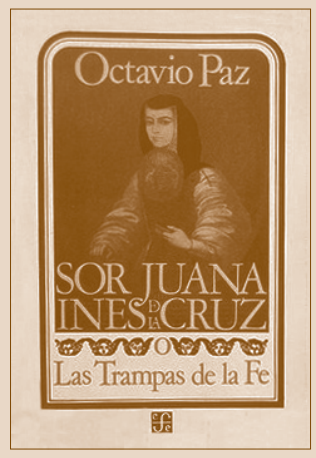

crítica contundente pero respetuosa y siempre precedida del elogio; porque, como aclara bien avanzado su ensayo (antes de referirse a la "pasión doctrinaria” que oscurecía los escritos del gran humanista mexicano):

... sin las versiones depuradas de los textos que nos ha dado Méndez Plancarte, sin sus notas a un tiempo eruditas e inteligentes, sin su saber y su sensibilidad, yo no habría podido escribir estas páginas. Llevó a cabo su admirable tarea gracias a su dedicación pero también al concurso de diversas cualidades conjugadas en su persona: la primera, su profundo y extenso conocimiento de la poesía de lengua castellana, especialmente en dos momentos de gran riqueza, el XVII y el modernismo hispanoamericano; la segunda, su curiosidad -pasión y paciencia- que lo llevó a penetrar en un territorio apenas explorado, sobre todo en su fase final: la poesía novohispana (1521-1721); la tercera, su saber en materia de versificación y de métrica, no inferior al de un Tomás Navarro Tomás o, entre los vivos, al de un Antonio Alatorre; la cuarta, su familiaridad con una de las fuentes de nuestra poesía en los siglos de oro: los poetas latinos, especialmente Horacio, del que tradujo cuarenta odas; la quinta, que fue la principal y el motor de las otras, su amor a la poesía. Un amor inteligente, servido por una erudición segura y un gusto casi siempre certero (Paz, 1995, pp. 365-366).

Ahora bien, la admiración sincera que demuestran estas palabras impli$\mathrm{ca}$, a su vez, una necesidad de elevarse a la altura del singular erudito a quien van dirigidas, de equiparar el trabajo propio al del máximo especialista en la obra de sor Juana: rebatir a Méndez Plancarte es, en cierto modo, continuar y superar su legado. Así se observa en la carta que escribe a Gimferrer, una vez finalizado el ensayo, reconociendo sus escrúpulos a publicarlo en España (recordemos que la decisión final sería esa edición doble en México y en Barcelona): Paz aduce en favor de la publicación en Fondo de Cultura Económica su amistad con el director de entonces, José Luis Martínez, pero confiesa que su principal motivo es que

... el Fondo de Cultura publicó una ejemplar edición crítica de sor Juana en 4 volúmenes y a mí me gustaría que mi libro apareciese, en el mismo formato, como una suerte de prolongación de esos cuatro tomos (29 de mayo de 1981; Paz, 1999, p. 219).

¿No fue ese el logro de Paz: marcar un antes y un después en los estudios sobre sor Juana? Y sin embargo, como recordaba Thomas R. Hart en su reseña de la traducción del ensayo al inglés, éste continuaba siendo "an 
intellectual's book addressed to cultivated general readers, not a scholar's book addressed to specialists" (1989, p. 397).

\section{LAS RESPUESTAS A PAZ: CONTINUIDAD DE LA POLÉMICA}

Escribía Asunción Lavrin en 1984 que, aunque Las trampas de la fe en realidad no ofrecía mucha información estrictamente novedosa sobre sor Juana, su autor había logrado ofrecer "a very appeling book wich will rekindle the fire of Sorjuanine estudies" (591). En efecto, tras la publicación del ensayo, la bibliografía sobre sor Juana se multiplica exponencialmente hasta el punto de resultar hoy día inabarcable. La influencia del libro de Paz se deja sentir en muy diversas líneas interpretativas (no siempre académicas ${ }^{20}$ ), incluso cuando algunas de ellas habrían podido desarrollarse más cabalmente a partir de otros modelos textuales ${ }^{21}$.

Otra consecuencia no de menor calado, planteada lúcidamente por Margo Glantz poco tiempo después de ser publicada la edición en inglés, es que, a partir de esta obra, resulta ya imposible ver a sor Juana fuera de la mirada del propio Paz:

In a very strange way, following the paths of Mexican history, Paz has achieved with his book an act of literary anthropophagy. He has assimilated Sor Juana, who is now utterly related to him and in a fascinating

\footnotetext{
${ }^{20}$ A este aspecto se refería Soriano Vallés en una entrevista relativamente reciente, atribuyendo (quizá de forma injusta) al ensayo de Paz una influencia negativa en la imagen que la monja novohispana ha ido adquiriendo hasta la actualidad: "Esta biografía suya, cuyo mérito fue originar un nuevo y extendido interés en la madre Juana, también es responsable de haberla vuelto (...) un ícono pop y, por ello, un producto light y, comúnmente, desechable. En tal sentido, se lo utiliza como pretexto para hablar de otras cosas; la generalidad de los productos que genera van encaminados a ensalzar algo más: el laicismo, el feminismo, la homosexualidad, etc. A partir de Octavio Paz, 'Sor Juana' ya no es Sor Juana, sino algo más” (en Baca, 2013, p. 101).

${ }^{21}$ Caso paradigmático en este sentido es el de la lectura "feminista" de sor Juana, que muy pronto se hizo eco de las conclusiones de Paz relegando trabajos precedentes en esta línea. Así, por ejemplo, en el libro Feminist Perspectives on Sor Juana Inés de la Cruz, la propia editora, Stephanie Merrim, incluye un artículo que comienza parafraseando el de Dorothy Schons "The first feminist in the New World" de 1925 (1991, p. 11) y reconoce en nota que algunas ideas de Paz habían sido adelantadas por dicha autora (32; nota 12), pero solo hace referencia a Schons en su argumentación a propósito de la Respuesta (29), mientras que el libro de Paz se convierte en eje central de la reflexión (al menos en su primera parte). De hecho, por más que en algún momento aparezca cierta crítica al ensayista mexicano ("Paz looks at Sor Juana, profoundly, in his way, as a woman, but not as a woman writer”, 1991, p. 20), el papel esencial que Merrim atribuye a este trabajo es evidente.
} 
perspective, has become, through a masterpiece of interwoven context, a part of his own poetry. Sor Juana cannot be spoken of now without thinking of Octavio Paz (1993, p. 130) ${ }^{22}$;

lo cual afecta sin duda al plano académico, en el que nuestro autor acaba convirtiéndose (como él mismo ambicionaba) en una "autoridad" difícilmente rebatible:

And even if some of his concepts about her could be disputed, his authority is so great that one thinks one is transgressing the law when one tries to contest his words (1993, p. 130).

En efecto, responder a la gran figura de las letras mexicanas (al menos en la década de los 90, y especialmente en el propio México) podía considerarse una "transgresión de la ley" ${ }^{23}$, y, sin embargo, casi de forma simultánea al citado texto de Glantz, se publicaron algunos trabajos cuyo propósito principal fue precisamente destacar errores del libro de Paz. En su artículo "Sor Juana ante el discurso paradójico: un ejemplo contemporáneo", Mónica Mansour puso en evidencia las contradicciones del autor tanto al ubicar a la monja novohispana en su contexto como al explicar su personalidad o valorar su producción literaria; para Mansour, el discurso de Paz resultaba tan ambivalente que "si se reorganizaran las interpretaciones y aseveraciones del autor de una manera distinta, el resultado serían dos libros con visiones opuestas" (1993, p. 379). Por su parte, una de las personalidades más polémicas del sorjuanismo, Antonio Alatorre, publicó en ese mismo volumen una "Lectura del Primero sueño" cuya primera parte era una demoledora crítica a la interpretación paciana del poema (Alatorre, 1993, pp. 101-111) para la que afirmaba haber buscado "el tono adecua-

\footnotetext{
${ }^{22}$ Uno de los más claros ejemplos de la forma en que la interpretación de Octavio Paz pudo opacar cualquier lectura anterior de la vida y la obra de sor Juana es el citado artículo de Goytisolo (1989) en el que se asumen plenamente (e incluso se radicalizan) las argumentaciones del autor mexicano.

${ }^{23}$ Por lo que respecta a la actitud de la propia Glantz, si bien la escritura misma de este artículo constituye ya una "transgresión", la investigadora mexicana es muy respetuosa con las ideas de Paz en sus estudios inmediatamente posteriores al mismo, como la edición de la Obra selecta de Sor Juana en Ayacucho (1994) y el monográfico Sor Juana Inés de la Cruz: ¿Hagiografía o autobiografía? (1995). De hecho, estos y otros trabajos posteriores representan una brillante forma de "respuesta" a los planteamientos de Paz, respuesta que es a un tiempo continuidad, perfeccionamiento o corrección a los mismos. Bastará citar a este respecto trabajos como "El jeroglífico del sentimiento: la poesía amorosa de Sor Juana” (2001), en el que recoge y amplía ideas del poeta sobre este asunto, o "Sor Juana: Los materiales afectos" (2005), donde rechaza la postura de Paz sobre la "impersonalidad" del alma en Primero sueño.
} 
do, o sea el tono del razonamiento tranquilo; un tono tal, que en ningún momento pudiera irritar a ese buen representante del genus irritabile que es Octavio Paz" (101), y un año más tarde aludía en otro artículo al citado debate entre Paz y Trabulse a propósito del hermetismo de sor Juana en los siguientes términos:

El avance en cuanto al conocimiento de sor Juana no lo veo por ningún lado. Sabíamos, antes de la polémica, que algunas noticias tenía sor Juana acerca del P. Atanasius Kircher. Y allí, justamente allí, es donde nos quedamos una vez leída la polémica" (Alatorre, 1994, p. 664) ${ }^{24}$.

Ahora bien, el hecho de que, como parte de su crítica, Alatorre enjuiciara una polémica previa alimentada por el propio Paz, nos lleva a la esencia misma de un ensayo que nace, como hemos visto, del debate con sus antecesores y que, como vaticinaba Benjamin Keen en 1989, "will provide material for reflection and debate for many years to come" (581). Por ello, aunque Las trampas de la fe esté dejando de ser el texto de referencia clave en las investigaciones sobre la obra de la monja novohispana ${ }^{25}$, lo cierto es que se halla todavía en el centro de algunas argumentaciones ${ }^{26}$ e incluso de arduas disputas que reavivan en algunos casos las promovidas por el ensayista mexicano, en especial la referente al "enigma" de esa supuesta "conversión" ascética de sor Juana en sus años finales, cuestionada por $\mathrm{Paz}^{27}$.

Cabe admitir en este sentido que, aunque por momentos excesivamente acalorada, la polémica sobre la posible influencia de los círculos del poder eclesiástico novohispano de fines del XVII en ese abandono de las letras por parte de sor Juana ha constituido un acicate para el hallazgo y/o edición de importantes documentos durante las dos últimas décadas, empezando por algunos textos en defensa de la Atenagórica, como la Carta de Sor Serafina

${ }^{24}$ Alatorre hace aquí referencia no a las páginas del ensayo de Paz sino al libro de Elías Trabulse donde se plasmó por primera vez dicha polémica: El hermetismo y sor Juana Inés de la Cruz: orígenes e interpretación, México, Litografía Regina de los Ángeles, 1980.

${ }^{25}$ Pienso, por ejemplo, en las necesarias pero escasas referencias a Paz en algunos libros relativamente recientes como los de Perelmuter (2004), Saldarriaga (2006) o Grossi (2007).

${ }^{26}$ Es el caso del artículo reciente de Dardo Scavino (2014), en el que el autor rebate la idea de Paz de que la interpretación de los ritos aztecas a la luz de las Sagradas Escrituras se deba al "presunto pluralismo liberal de los criollos" para considerarla más bien "una absorción en la mismidad cristiana” (2014, p. 27).

${ }^{27}$ Dicha disputa surgió con las primeras lecturas del ensayo (Bénassy-Berling, 1983, pp. 98100; Haslam 1989, p. 337) y tuvo un momento álgido en 1995, durante los numerosos encuentros académicos con motivo del aniversario de la muerte de sor Juana, pero hay también ejemplos recientes de la misma como las intervenciones de Soriano Vallés en el número 21 de la revista Ritmo (2013). 
de Cristo (hallada en 1995 por Elías Trabulse y atribuida erróneamente a la propia sor Juana, como demostraron tres años después Antonio Alatorre y Martha Lilia Tenorio ${ }^{28}$ ) o la Defensa del Sermón del Mandato, de Pedro Muñoz de Castro, y el anónimo Discurso apologético en respuesta a la Fe de erratas que sacó un soldado sobre la Carta Atenagórica de la madre Juana Inés de la Cruz, ambos sacados a la luz por Rodríguez Garrido (2004), quien atribuye el segundo a un sacerdote amigo de Sor Juana, Francisco Xavier Palavicino $^{29}$. Documentos a los que cabe añadir el Libro de profesiones del convento de San Jerónimo de México, recientemente editado por parte de Guillermo Schmidhuber (2013) y las Cartas de Puebla y San Miguel, escritas por Fernández de Santa Cruz, dadas a conocer por Alejandro Soriano Vallés junto a la cláusula 20 del testamento de José de Lombeyda, en la que se hace referencia a los libros entregados por Sor Juana para su venta que todavía quedaban en poder de dicho presbítero en el momento de su muerte (2012, pp. 299-371).

La interpretación de todos estos documentos continuará dando materia a los especialistas para apoyar o rebatir a Paz. Así, por ejemplo, a mi modo de ver, las diversas cartas en defensa de sor Juana y su Atenagórica demuestran que no todos los miembros de la jerarquía eclesiástica vieron con malos ojos este escrito teológico de la monja jerónima (e incluso, a tenor de lo que podemos consultar hasta ahora, que fueron más los que la defendieron ${ }^{30}$ ), y que, por tanto, la teoría de la "conspiración" por parte de las autoridades religiosas que defendió Paz debería ser como mínimo matizada; sin embargo, la cláusula del testamento de Lombeyda, presentada por Soriano Vallés como "irrefutable evidencia de que a la Décima Musa jamás le arrebataron la biblioteca" (2013, p. 99) no lo es en absoluto: solo indica que la monja le "entregó distintos libros [de forma libre o coaccionada] para que los vendiese" y que él procedió a dicha venta "en virtud de mandato del Ilustrísimo señor arzobispo" (apéndice 4 de Soriano Vallés, 2012, p. 369) sin demasiadas prisas, ya que, una vez fallecido, todavía quedaban ejemplares que tuvieron que ser entregados a Aguiar. Por otro lado, las cartas de Fernández de Santa Cruz a Sor Juana resultan reveladoras: la firmada

${ }^{28}$ Cf. Trabulse (1996) y Alatorre y Tenorio (1998).

${ }^{29}$ Sin duda la edición de Rodríguez Garrido (2004) es un modelo a seguir: incluye en CD la digitalización de los manuscritos citados para su posible estudio posterior por parte de otros investigadores.

${ }^{30}$ A pesar de su título, incluso la Defensa del Sermón del Mandato de Pedro Muñoz de Castro (en Rodríguez Garrido, 2004, pp. 125-151) parte de la alabanza a sor Juana. 
en Puebla en marzo de 1691 muestra al obispo como pleno defensor de la actividad intelectual de su amiga, cuya Respuesta ha leído atentamente; por ello le "receta"

... el más lenitivo remedio, que es que estudie más hoy, que sepa más. ¿Cómo podría V. md. Negarse a remedio, que es el más agradable cebo a su inclinación? Para curar accidente que ocasionó el estudio, la aconsejo que estudie prácticamente dos horas al día en la Mística Teología (Soriano Vallés, 2012, p. 349) ${ }^{31}$.

Las ciencias de las que habla sor Juana en su Respuesta "ilustran el entendimiento, ésta [la Teología] da sabor a la voluntad"; además "tiene otra ventaja esta ciencia: que al estudioso nunca le falta Maestro que la enseñe (...), que es Dios" (354-355). Al año siguiente (en enero de 1692) llega a proponerle un nuevo tema para su reflexión (una segunda "Atenagórica"):

... pues está en estado de poder enseñar, no dé pasos ociosos al aprender. Cíñase con constancia a un asunto, donde mezcle V. md. algo afectivo de la voluntad y a que pueda reducir las más especiosas noticias de cuanto ha leído; el que a mí se me ofrece es amparo y desamparo de Dios en Saúl, en que puede V. md. explayarse en documentos políticos, morales y místicos (Soriano Vallés, 2012, pp. 359-360).

Ambos textos desmienten las afirmaciones de Paz sobre la postura del obispo de Puebla tras la recepción de la Respuesta: "La actitud de Fernández de Santa Cruz reveló una cautela que colindaba con la doblez y la hipocresía. No contestó a la carta de su protegida" (Paz, 1995, p. 551). Pero también explican las dudas del ensayista mexicano antes de lanzarse a buscar los posibles motivos del obispo: dicho silencio era, para Paz "tanto más extraño cuanto que la Respuesta era un escrito excepcional (...). El desdén que sucedió a la Respuesta contrasta extrañamente con la atención cariñosa aunque exigente de antes" (551). Conocer el contenido de dichas epístolas le habría permitido confirmar la relación de amistad sincera que intuía entre sor Juana y "sor Filotea"; no en vano advertía Ramón Xirau a los pocos meses de su publicación, que las páginas del ensayo de Paz estaban "llenas de argumentaciones, vislumbres, matices” (1997, p. 146. La cursiva es mía).

\footnotetext{
${ }^{31}$ Modernizo la ortografía en todas las citas de estas cartas de Fernández de Santa Cruz.
} 


\section{UNA ÚLTIMA REFLEXIÓN: SOR JUANA INÉS DE LA CRUZ Y OCTAVIO PAZ}

Cabe finalizar estas líneas volviendo, pues, al carácter ambiguo de un ensayo literario que se pretende trabajo académico, carácter que fue incluso motivo de elogio tras su publicación ${ }^{32}$ pero que se ha convertido en el talón de Aquiles de la obra para sus detractores ${ }^{33}$ y que, en cualquier caso, debe llevarnos a su vez a una lectura del mismo distinta a la planteada en los apartados anteriores, porque, en la medida en que la obra se configura como lectura personal de Paz, podemos centrar nuestra atención en el hecho -ya señalado asimismo por Xirau en esa reseña pionera- de que en ella no solo está presente sor Juana y su mundo, "está también presente Octavio Paz y, hasta cierta medida, Paz también es sor Juana" (1997, p. 158) ${ }^{34}$.

${ }^{32}$ Recordemos, por ejemplo, cómo Luciani matizaba sus objeciones al texto desde su perspectiva de investigador para concluir que "pedir una crítica sistemática y las fórmulas del mundo académico al estudio de Paz sería, en efecto, pedir peras al olmo y pasar por alto una de las mayores virtudes del libro: su subjetividad" (1985, p. 398).

${ }^{33}$ Así, Soriano Vallés afirmaba recientemente a este respecto: “Octavio Paz inauguró el modo de hacer crítica que caracteriza a la era posterior a él. Puso en boga el "método" que un analista llamó "lógica incremental", es decir, "los vacíos generan hipótesis sobre hipótesis que se afirman luego como «verdades»". Lo cual, con otras palabras, significa que se otorga a una mera conjetura el carácter sólido de prueba. Tan extravagante "método" es parte del gran éxito alcanzado por las Trampas de Paz, pues le permitió "explicar", a su modo y sin tener que acudir al incómodo expediente de la demostración científica, situaciones históricas que no concordaban con la visión de Sor Juana que él quería presentar” (en Baca, 2013, p. 100; cf. Mansour, 1993, p. 378). Cabe considerar, sin embargo, que, aunque estuviéramos de acuerdo con la afirmación de Soriano, lo cierto es que no le cabría a Paz el "honor" de haber inaugurado la interpretación no documentada de la obra de sor Juana: la bibliografía sobre la monja novohispana se ha caracterizado por la afirmación de hipótesis (e incluso de absolutas fabulaciones) desde fechas muy tempranas, y no precisamente en textos de carácter ensayístico, sino en los "oficialmente" académicos. Buen ejemplo de ello nos da Antonio Alatorre en el curioso recorrido que realiza por los plagios, repeticiones acríticas e incluso ampliaciones que se hicieron a lo largo del siglo XIX de los datos biográficos claramente inventados por José Bocous para la entrada sobre sor Juana en el tercer tomo de la Biographie Universelle, publicada en 1819 y traducida al castellano en 1831; dicho recorrido sirve a Alatorre para referirse a supuestas "novedades" interpretativas contemporáneas entre las que se encuentran algunas del propio Paz (Alatorre y Tenorio, 1998, pp. 120-121), pero recordando que "convertir sin más las hipótesis en otras tantas singularidades" es en realidad "lo propio del 'sello Bocous"” (119). En otro artículo, en cambio, el mismo Alatorre se refiere no tanto a las hipótesis de Paz como a su "tono poético" (no filológico) a propósito del Primero sueño, y advierte: "lo que ocurre es que Paz, como poeta que es, gusta mucho de caracterizaciones o definiciones que yo llamaría metafóricas o imaginativas (...). Acostumbrado como estoy a otra clase de lenguaje crítico, no me siento preparado aquí para acompañar a Paz, para captar su pensamiento. No puedo asentir ni disentir: sencillamente no entiendo" (1994, p. 104).

${ }^{34}$ En el mismo sentido se expresaron Luciani, quien habló del ensayo como de "un espejo donde Paz se examina a sí mismo en la figura de la monja" (1985: 398), o Hart, para el que "Students of Paz's poetry, and especially of his essays, will surely read his Sor Juana much as students of Valery read 'The Method of Leonardo da Vinci', not so much for information about Leonardo as for insights into the mind of Valery himself" (1989, p. 397). 
A este otro tipo de lectura, que indaga sobre lo que Paz nos dice de sí mismo en el texto, obedecen trabajos como los de Enrico Mario Santí y, a partir de este, Mónica Quijano, quienes han analizado el ensayo desde un enfoque político-ideológico ${ }^{35}$ para concluir que el carácter "ejemplar" de los años finales de sor Juana y su comparación con la coacción sufrida por numerosos intelectuales del siglo XX (en especial por parte de la burocracia comunista) revela una preocupación política de Paz que, probablemente, tiene su origen en ese distanciamiento respecto al estalinismo que el poeta estaba viviendo por los años en los que escribió su primer ensayo sobre la autora novohispana, cuyo detonante debió ser la polémica en Francia sobre la existencia de los campos de concentración soviéticos (1949) y la actitud mostrada en ese contexto por intelectuales como Sartre o Merleau-Ponty (Santí, 1997, pp. 277-279), pero que guardaría también relación con toda una "reflexión sobre la función del Estado y sobre la relación entre política e historia, que lo lleva a revisar sus posturas frente al marxismo y al socialismo soviético durante la década de 1970" (Quijano, 2009, p. 21), volcada en sus ensayos de El ogro filantrópico (Quijano, 2009, pp. 21-25).

Desde una perspectiva propiamente literaria, resulta, a su vez, revelador un artículo de Teodosio Fernández, "Lectura surrealista del barroco: Sor Juana Inés de la Cruz y Octavio Paz", en el que el autor rebate las ideas de Paz sobre la vinculación de Sor Juana con una tradición hermética que la colocaría al borde de la herejía y propone que en realidad el interés de Paz por establecer dicha vinculación obedece a un intento de insertar a la monja novohispana en una corriente poética que llevaría hasta el surrealismo: "Los esfuerzos hermenéuticos de Paz -escribe Fernández-adquieren pleno sentido si se advierte que se trataba de llevar a Sor Juana hasta 'la gran familia de los iluministas' elaborada por Breton" (2010, p. 117), lo cual suponía a su vez colocar a sor Juana en la tradición de la que surge la obra poética del propio Paz.

La argumentación de Fernández, quien considera necesario leer hoy las páginas de este ensayo "como una ficción literaria de Octavio Paz, de notable significación autobiográfica" (2010, p. 109), nos lleva a su vez a una pregunta todavía más esencial sobre él mismo: ¿por qué Paz elige dedicar su

\footnotetext{
${ }^{35}$ De hecho, Santí define en principio el libro como biografía, tratado de revisión histórica y “ensayo de crítica política y moral” (1997, p. 18), y advierte, al abordarlo ya detenidamente: “Que la interpretación de Paz constituye, entre otras cosas, una lectura política merece ser subrayado. La mayoría de las reseñas que se han publicado -incluso las que han salido en México- han obviado este aspecto" (283).
} 
principal ensayo a sor Juana Inés de la Cruz? El propio autor finalizaba su prólogo con una hermosa fórmula de captatio benevolentiae:

Mi ensayo es una tentativa de restitución ${ }^{36}$ (...). Restitución: sor Juana en su mundo y nosotros en su mundo. Ensayo: esta restitución es histórica, relativa, parcial. Un mexicano del siglo XX lee la obra de una monja de la Nueva España del siglo XVII. Podemos comenzar.

Resulta evidente, sin embargo, que Paz no es solo "un mexicano del siglo XX", y que la restitución de sor Juana tiene que ver también con una concepción de sí mismo como poeta y como intelectual en un marco (al igual que le ocurrió a sor Juana en su época) mucho más amplio que el estrictamente mexicano. Sor Juana es única; Octavio Paz también. Tras la publicación del ensayo, Georgina Sabat se congratulaba:

Sor Juana está de fiesta: la personalidad más importante y conocida del pensamiento hispanoamericano actual ha caído irremisiblemente bajo su fascinación $\left(1985\right.$, p. 423) ${ }^{37}$.

¿No era ese elogio la pretensión íntima de Paz? Escribía Margo Glantz en su artículo de 1993: "for the only writer that Paz is able to accept as his ancestor in Mexico is Sor Juana, and when he writes about her, he is trying to discover himself in her" (130). Tras las "humildes" palabras del prólogo de Paz podemos interpretar entonces: el intelectual latinoamericano más relevante del siglo XX lee a la que fue máxima figura de las letras virreinales ( $y$, al hacerlo, se lee también a sí mismo). Ahora sí podemos comenzar.

\section{REFERENCIAS}

Alatorre, A. (1993). "Lectura del Primero Sueño". En S. Poot (ed.). Y diversa de mí misma entre vuestras plumas ando. Homenaje internacional a Sor Juana Inés de la Cruz. México: El Colegio de México, 101-126.

\footnotetext{
${ }^{36}$ Sobre el concepto de restitución en el ensayo de Paz y, de forma más general, en la bibliografía crítica sobre Sor Juana, es de gran interés el citado trabajo de Santí (1997).

${ }^{37}$ Afirmación que no distaba mucho de la que, con un claro tono panegírico, había realizado Francisco Rivera en una de las primeras reseñas al ensayo, publicada en Vuelta, la revista del propio Paz: "Había (...), más de una razón para que un coterráneo de sor Juana, pero no uno cualquiera, sino el mayor poeta y ensayista latinoamericano de la segunda mitad del siglo XX, sintiese la necesidad de escribir acerca de [sor Juana]" (1983, p. 41).
} 
Alatorre, A. (1994). "Avances en el conocimiento de Sor Juana”. En J. Ortega y J. Amor y Vázquez (Eds.). Conquista y contraconquista: la escritura en el Nuevo Mundo (pp. 659-667). México: Brown University.

Alatorre, A. y Tenorio, M. L. (1998). Serafina y Sor Juana. México: El Colegio de México.

Alazraki, J. (1984). “Octavio Paz’s Sor Juana Inés De La Cruz: An Intellectual Feast". World Literature Today. A Literary Quarterly of the University of Oklahoma, 58(2), 225-227.

Baca, H. (2013). Entrevista con Alejandro Soriano Vallés. La pasión y la crítica. Ritmo. Imaginación y crítica, 21 (noviembre), 96-108. Disponible en http:// issuu.com/revistaritmo/docs/ritmo21 [última fecha de consulta: 12/01/15]

Bénassy-Berling, M-C. (1983). "Octavio Paz, Sor Juana Inés de la Cruz o Las trampas de la fe". Caravelle. Cahiers du Monde Hispanique et Luso-Brésilien, 41, 97-102.

Calleja, D. (1700). Aprobación del reverendísimo padre Diego Calleja de la Compañía de Jesús a la Fama y obras póstumas del Fénix de México, décima musa, poetisa americana, sor Juana Inés de la Cruz... / conságralas... Don Juan Ignacio de Castorena y Ursúa... Madrid: en la Imprenta de Manuel Ruiz de Murga, s/n. Disponible en http://ds.ub.uni-bielefeld.de/viewer/image/1592397/10/ a http://ds.ub.uni-bielefeld.de/viewer/image/1592397/20/ [última fecha de consulta: 12/01/15].

Cruz, Sor Juana Inés de la (1957). Obras completas IV. Comedias, sainetes y prosa. México: FCE.

Fernández, T. (2010). "Lectura surrealista del barroco: Sor Juana Inés de la Cruz y Octavio Paz". En J. M. Ferri y J. C. Rovira (Coords.). Parnaso de dos mundos: de literatura española e hispanoamericana en el Siglo de Oro. Madrid/Frankfurt: Iberoamericana/Vervuert, 95-122.

Glantz, M. (1993). “Octavio Paz and Sor Juana Inés de La Cruz’s Posthumous Fame”. Pacific Coast Philology, 28(2) (Oct.), 129-137.

Glantz, M. (1994). Prólogo a Sor Juana Inés de la Cruz. Obra selecta I. Caracas: Ayacucho, XI-XC.

Glantz, M. (1995). Sor Juana Inés de la Cruz: ¿Hagiografía o autobiografía? México: Grijalbo/UNAM. Disponible en http://www.cervantesvirtual.com/ nd/ark:/59851/bmc1r729 [última fecha de consulta: 12/01/15].

Glantz, M. (2001). "El jeroglífico del sentimiento: la poesía amorosa de Sor Juana”. En J. Pascual Buxó (Ed.). La producción simbólica en la América Colonial: interrelación de la literatura y las artes. México: UNAM, Instituto de Investigaciones Bibliográficas, Seminario de Cultura Literaria Novohispana, CONACYT, 115-127. Disponible en http://www.cervantesvirtual.com/obra/el-jeroglfico-del-sentimiento---la-poesa-amorosa-desor-juana-0/ [última fecha de consulta: 12/01/15].

Glantz, M. (2005). "Sor Juana: Los materiales afectos". En S. Lorenzano (Ed.), Aproximaciones a Sor Juana. México: FCE/Universidad del Claustro de Sor Juana, 109-123. 
Goytisolo, J. (1989). "Una heroína de nuestro tiempo. (Notas sobre Sor Juana Inés de la Cruz o Las trampas de la fe, de Octavio Paz)". Quimera, 86, 20-27.

Grossi, V. (2007). Sigilosos v(u)elos epistemológicos en Sor Juana Inés de la Cruz. Madrid/Frankfurt: Iberoamericana/Vervuert.

Hart, T. (1989). Sor Juana, Or the Traps of Faith. By Octavio Paz. Comparative Literature 41, 4 (Autumn), 397-399.

Haslam, G. W. (1989). Sor Juana, or the Traps of Faith by Octavio Paz. Tulsa Studies in Women's Literature, 8(2) (Autumn), 334-338.

Keen, B. (1989). Sor Juana Or the Traps of Faith. By Octavio Paz. The Hispanic American Historical Review, 69(3) (Aug.), 580-581.

Lavrin, A. (1984). "Sor Juana Inés de la Cruz o Las trampas de la fe, by Octavio Paz". The Americas. A Quarterly Review of Inter-American Cultural History, 40(4) (Apr.), 589-591.

Liano, D. (1984). "La Sor Juana De Octavio Paz". Quaderni Di Letterature Iberiche e Iberoamericane, 2, 102-107.

Luciani, F. (1985). “Octavio Paz, Sor Juana Inés de la Cruz o Las trampas de la fe”. Revista Iberoamericana, 51 (Jan.), 396-398.

Mansour, M. (1993). "Sor Juana ante el discurso paradójico: un ejemplo contemporáneo". En S. Poot (ed.). Y diversa de mí misma entre vuestras plumas ando. Homenaje internacional a Sor Juana Inés de la Cruz. México: El Colegio de México, 367-379.

Méndez Plancarte, A. (1951). Introducción a Sor Juana Inés de la Cruz. Obras completas I. Lírica Personal. México: FCE, VII-LXVIII.

Merrim, S. (Ed. (1999). Feminist Perspectives on Sor Juana Inés de la Cruz. Detroit, Mich.: Wayne State University Press.

Mistral, G. (1951). "Silueta de Sor Juana Inés [1923]”. Ábside, 15, 4 (OctubreDiciembre), 501-506. Disponible en http://www.dartmouth.edu/ sorjuana/ Commentaries/Mistral/Mistral.html [última fecha de consulta: 12/01/15].

Ontañón, P. (1999). "Sor Juana, víctima de los críticos”. Revista de Filología Española, LXXIX, 1/2, 181-190.

Paz, O. (1950). El laberinto de la soledad. México: Cuadernos Americanos.

Paz, O. (1951). "Homenaje a Sor Juana Inés de la Cruz en su Tercer Centenario (1651-1695)”. Sur, 206 (diciembre), 29-40. Disponible en http://www.dartmouth.edu/ sorjuana/Commentaries/Paz/Paz.html [última fecha de consulta: $12 / 01 / 15]$.

Paz, O. (1995). Sor Juana Inés de la Cruz o Las trampas de la fe, Barcelona: Seix Barral.

Paz, O. (1999). Memorias y palabras. Cartas a Pere Gimferrer 1966-1997 (prefacio de B. Baltasar; edición, prólogo y notas de P. Gimferrer). Barcelona: Seix Barral.

Paz, O. (2001). Obras completas III. Generaciones y semblanzas. Dominio mexicano. Sor Juana Inés de la Cruz o las trampas de la fe. Barcelona: Galaxia Gutenberg/Círculo de Lectores.

Perelmuter, R. (2004). Los límites de la femineidad en Sor Juana Inés de la Cruz: 
estrategias retóricas y recepción literaria. Madrid/Frankfurt: Iberoamericana/ Vervuert.

Quijano Velasco, M. (2009). “Sor Juana Inés de la Cruz o las trampas de la fe: una fábula intelectual”. Iberoamericana, IX, 33, 7-26.

Rivera, F. (1983). "Octavio Paz. Sor Juana Inés de la Cruz o las trampas de la fe". Vuelta, 7(78), 41-43.

Rodríguez Garrido, J. A. (2004). La Carta atenagórica de Sor Juana. Textos inéditos de una polémica. México: UNAM.

Sabat, G. (1985). Octavio Paz ante Sor Juana Inés de la Cruz. MLN, 100, 417423.

Sabat, G. (1995). Sobre la versión inglesa de Las trampas de la fe de Octavio Paz. En Bibliografía y otras cuestiúnculas sorjuaninas. Argentina: Biblioteca de Textos Universitarios, 106-120. Disponible en http://www.cervantesvirtual. com/obra-visor-din/bibliografia-y-otras-cuestiunculas-sorjuaninas--0/ html/5381alf0-e18d-402b-9bcf-0049b36e3010_21.html\#I_27_ [última fecha de consulta: $12 / 01 / 15]$.

Saldarriaga, P. (2006). “Los espacios del 'Primero sueño' de Sor Juana Inés de la Cruz". Madrid/Frankfurt: Iberoamericana/Vervuert.

Santí, E. M. (1997). “Sor Juana, Octavio Paz y la poética de la restitución”. En El acto de las palabras. Estudios y diálogos con Octavio Paz (pp. 258-300). México: FCE.

Scavino, D. (2014). "Sor Juana Inés de la Cruz y el espejo de los enigmas". Anclajes, XVIII, 1 (jun.), 27-45.

Schmidhuber de la Mora, G. (colaboración de Peña Doria, O. M.) (2013). De Juana Inés de Asuaje a Juana Inés de la Cruz. El libro de profesiones del convento de San Jerónimo de México. México: Instituto Mexiquense de Cultura.

Soriano Vallés, A. (2012). Aquella fénix más rara: vida de Sor Juana Inés de la Cruz. México: Minos Tercer Milenio.

Soriano Vallés, A. (2013). "Sor Juana”. Ritmo. Imaginación y crítica, 21 (noviembre), 78-89. Disponible en http://issuu.com/revistaritmo/docs/ritmo21 [última fecha de consulta: 12/01/15].

Xirau, R. (1997). “La sor Juana de Octavio Paz [1982]”. En Genio y figura de Sor Juana Inés de la Cruz (pp. 147-158). México: UNAM. 